Volume 10, No.5, September - October 2021

International Journal of Advanced Trends in Computer Science and Engineering

Available Online at http://www.warse.org/IJATCSE/static/pdf/file/ijatcse071052021.pdf

https://doi.org/10.30534/ijatcse/2021/071052021

\title{
Information Technology Student's Perception Toward E-Learning During Pandemic Covid-19
}

\author{
Siti Sharmila Osmin ${ }^{1}$ \\ Politeknik Ungku Omar \\ milaosmin@puo.edu.my
}

Received Date : August 04, 2021 Accepted Date : September 17, 2021 Published Date : October 06, 2021

\begin{abstract}
The outbreak of COVID-19 has had a significant impact on the educational system around the world. It prompted the closure of educational institutions, which had a negative impact on the student activities all over the world. COVID-19 required confinement and isolation due to its infectious nature thus imposed seclusion, which has a significant impact on lecturers and student's personal interactions. The quantitative approach has been adopted and responses using the data that collected through online questionnaires from 200 students from Department of Information technology and Communication at Politeknik Ungku Omar. This research was conducted during August - September 2021 and the data were recorded in SPSS and analyzed using descriptive statistics. This study reveals that the most difficulties in e-Learning to adjust their learning styles and maintain focus. Moreover, students also most of the students have less motivation when learning online compared to face-to-face learning. The mean perceived in the differences of perceptions according to gender, household income and area of residence are also have significantly different. this study reveals that most students satisfied with the lecturer's teaching delivery through online platform. This item scores the highest score mean among other items. Most students recommend reducing workload and providing longer assessment times to improve motivation in an e-Learning environment. By giving light on the perspective of diploma students, the findings of this study add to current studies on students' perspectives and preferences for e-Learning education.
\end{abstract}

Key words: Student's perception, e-Learning, COVID-19, survey study

\section{INTRODUCTION}

The outbreak and global spread of a novel coronavirus (COVID-19) so contagious and harmful that the World Health Organization (WHO) declared a global pandemic at the beginning of the year 2020. This catastrophe has also rattled the education sector, and this panic is likely to spread throughout the world's education system. Many schools and Higher Education Institutes (HEIs) were forced to close temporarily due to the Covid-19 pandemic. According to [12] the use of technology and network connectivity for teaching and learning is referred to as E-learning. Consequently, E-learning is becoming part of a larger category of technology-based learning that includes websites, learning portals, video conferencing, and so on. In research from [19], this situation has given educators the option to incorporate IT solutions for teaching as well as evaluation for students' completion of course work. Students and educational institutions all around the world have embraced and welcomed the online learning platform. The ease of use, learning flexibility, and customizable environment are the reasons for its acceptability.

According to [11] the goal is to minimize the learning gap that arouse due to lockdown. Students and educational institutions all around the world have embraced and welcomed the online learning platform. The ease of use, learning flexibility, and customizable environment are the reasons for its acceptability. The use of E-learning shows a positive impact on student learning [4], [25]. Despite the advantage given by an average higher computer literacy, that students found the transition challenging, especially regarding tasks such as asking questions during video lectures and interacting with instructors [22]. In research from [8], "e-learning crack-up" perception has a significant positive impact on student's psychological distress, and fear of academic year loss is the crucial factor that is responsible for psychological distress during COVID-19 lockdown. As a matter of fact, E-learning is already in the adapting phase for both educators and students. Aggressively, this teaching and learning style is being adopted by students whether there is ready or not. During the COVID-19 epidemic, however, providing and using online learning materials in an e-learning system has become a compulsory in education.

Because of its ubiquity (availability anywhere and at any time), low cost, ease of use, and interactive nature, the E-learning system is an essential method of learning for nowadays situation. In this paper, we will focus on identifying the perception of students of Department of Information 
Technology and Communication at Politeknik Ungku Omar toward E-learning during Pandemic Covid-19. In theory, this department should be in a better position to transition of E-learning quickly and effectively than other departments, because students have higher levels of computer literacy on average than other students from another department. Additionally, most of the lecturers already use online tools for a variety of tasks, such as assigning and collecting homework and sharing course material. Our study also shows differences in perception across the student's demographic and these results can helps identify the most vulnerable area in e-Learning environment.

\section{LITERATURE REVIEW}

Since the objective of e-learning is to allow students to learn and complete their courses without physically attending a traditional on-campus academic setting, it was only appropriate to use is during the COVID-19 pandemic as a preventive precaution [16]. E-learning programs and courses were already available for people who were mentally and economically ready for such learning [6]. Regardless of how well the educational institutions are prepared to promote the use of e-learning systems, other COVID-19-related challenges play a crucial role in forming the intention of students to participate in e-learning during the COVID-19 pandemic [13]. According to research done by [15], learners are not satisfied with continuing online learning, as they could not fulfil the expected progress in language learning performance. Therefore, students can overcome some of the possible problems offered by online learning by developing strong attitudes toward learning, such as remaining focused during online classes or retaining appropriate motivation. In research from [20], the study showed that some students tend to detest online learning due to the challenges of personal and technological difficulty issues. Besides, distance learning has also been found to be related to psychological impact such as stress and anxiety. Online learning in its entirety is dependent on technological devices and internet, instructors and students with bad internet connections are liable to be denied access to online leaning [2].

In research from [9] the perspective of university management, an online learning environment under emergency management represents an advantageous turning point in promoting the development of online learning. Furthermore, lecturers adopted online learning to continue teaching during the pandemic, and their help, attention, or advice during online teaching sessions formed motivation for students to switch to online learning. It is suggested by [24] converting a small number of classes to e-learning can decrease potential for disease transmission while minimizing disruption to university operations. Moreover, satisfactory attitude of students depends on the ease of use of these distance learning apps because the easier the apps are to use, the more motivated the students will be to use them [It is agreed by [23] several social media platforms, including as Twitter, Instagram, Facebook, and WhatsApp, have aided teachers and students in fostering supportive, collaborative learning and information sharing. Students have a generally good attitude toward e-learning, according to the study and it is found that e-learning programme are also attracting a lot of attention and are being used more frequently in academic settings [17]. According to [14] the research found that students believe that e-learning aids their learning and fortunately, E-learning can reduce educator's workload while increasing student workload.

\section{METHODOLOGY}

The study is conducted in Department of Information Technology and Communication, one of department of Ungku Omar Polytechnic, a Technical and Vocational Educational Training (TVET) institution in Malaysia. Because of the pandemic, we relied on online surveys for our research. Due to the Malaysian government's movement control order, they have had to attend classes online from their residences from March 2020. This research was carried out between the July 2021 and the September 2021. The students had completed almost 1 year and five months of fully online learning by this point. CIDOS (Learning Management System) have been used as the main management learning system beside other application such as Google Classroom, Watsapp, telegram and many more.

The questionnaires consisted of five sections. The first section collects the demographic information of the students while the rest of the sections gauges the student's perception (benefits, satisfaction, and challenges) of e-learning during Covid-19 Pandemic. Cronbach's alpha test is used to determine the factors' reliability and internal consistency. Table 1 shows the Cronbach's alpha value for each of the constructs independently and the reliability values of the Cronbach's alpha are 0.835 (satisfaction), 0.918 (benefits) and 0.859 (challenges). The Cronbach's alpha values between 0.70 to 0.90 exceed the level of acceptability [21]. The data shown here was compiled using SPSS Output by the researchers. The link to the surveys is shared on the institution's primary social media channels, which are utilized to communicate any information to students. The collected data was then examined using SPSS software for further analysis. The study employed cross-sectional online survey that collected data at the same time. Because the scope of this study was diploma students from the same institution who were experiencing e-learning during COVID-19 pandemic, a sample approach was chosen. The online questionnaire utilized in this study began with an introduction that informed respondents about the survey's objective and assured them of their privacy and confidentiality. The questionnaires were using multiple choice and five-point Likert scale questions, and it is adjusted and adapted from [18], [11]. 
Table 1: Questionnaires Reliability

\begin{tabular}{l|cc}
\hline Section & Cronbach's Alpha & No. of items \\
\hline Satisfaction & 0.835 & 4 \\
Benefits & 0.918 & 12 \\
Challenges & 0.859 & 6 \\
\hline
\end{tabular}

Table 2 shows the demographic characteristics of 187 respondents. During the pandemic, most students (61\%) lived in urban areas and have access to the Internet for their e-learning activities (93\%). Nearly $63 \%$ of the students had at a fair connection of internet signal strength. For total spending time for e-Learning, $52.9 \%$ of them spend less than 5 hours per day for online learning, which is the projected average daily learning time based on the students' learning schedules. The household income of students was divided into three categories: B40 (less than RM 4,849), M40 (RM 4,850 to RM 10,959), and T40 (greater than RM 4,849). (RM 10,960 or more). More than half of the students are categorized as M40 (Middle income).

Table 2: Demographic Characteristics $(N=187)$

\begin{tabular}{|c|c|c|c|}
\hline Variables & Categories & $\begin{array}{c}\text { Frequency } \\
\text { Distribution }\end{array}$ & Percentage \\
\hline \multirow[t]{2}{*}{ Gender } & Male & 112 & 59.9 \\
\hline & Female & 75 & 40.1 \\
\hline \multirow{3}{*}{ Diploma Cluster } & Information Security & 48 & 25.7 \\
\hline & Network System & 54 & 28.9 \\
\hline & $\begin{array}{l}\text { Software and Application } \\
\text { Development }\end{array}$ & 85 & 45.5 \\
\hline \multirow{5}{*}{ Semester } & One & 0 & 0 \\
\hline & Two & 15 & 8.0 \\
\hline & Three & 45 & 24.1 \\
\hline & Four & 24 & 12.8 \\
\hline & Five & 103 & 55.1 \\
\hline \multirow{5}{*}{$\begin{array}{l}\text { Area of residency } \\
\text { Device use for e-learning }\end{array}$} & Rural & 73 & 39.0 \\
\hline & Urban & 114 & 61.0 \\
\hline & Desktop computer & 7 & 3.7 \\
\hline & Laptop & 167 & 89.3 \\
\hline & Smartphone & 13 & 7.0 \\
\hline \multirow{2}{*}{ Internet access at home } & Available & 174 & 93.0 \\
\hline & Not available & 13 & 7.0 \\
\hline \multirow{3}{*}{ Internet signal strength } & Poor & 12 & 6.4 \\
\hline & Fair & 117 & 62.6 \\
\hline & Good & 58 & 31.0 \\
\hline \multirow{5}{*}{$\begin{array}{l}\text { Daily hour spent for e- } \\
\text { learning }\end{array}$} & Less than 5 hours & 99 & 52.9 \\
\hline & 5 to 8 hours & 46 & 24.6 \\
\hline & 9 to 12 hours & 25 & 13.4 \\
\hline & More than 12 hours & 17 & 9.1 \\
\hline & B40 (Low income) & 101 & 54.0 \\
\hline \multirow{2}{*}{$\begin{array}{l}\text { Household income } \\
\text { category }\end{array}$} & M40 (Middle income) & 82 & 43.9 \\
\hline & T40 (High income) & 4 & 2.1 \\
\hline \multirow{4}{*}{$\begin{array}{l}\text { Preferred platform for live } \\
\text { video session with } \\
\text { lecturers: }\end{array}$} & Google Meet & 148 & 79.1 \\
\hline & Zoom & 36 & 19.3 \\
\hline & MS Team & 3 & 1.6 \\
\hline & Cisco WebEx & 0 & 0 \\
\hline
\end{tabular}

\section{RESULT AND DISCUSSION}

\subsection{Student's Perception toward E-learning: Satisfaction}

Three categories of student's perception on E-learning during the pandemic Covid-19 were investigated. The categories are satisfaction, benefits, and challenges. For the first perception regarding satisfaction, the result of the Likert's scale questions is display in Table 3. Students' intentions to continue studying through the online medium had the most negative perception $(2.97$, with only $34.4 \%$ of the students expressing interest, and the mean score for it was likewise the lowest compared to the other elements. Previous studies found similar results with most of the respondents stating that they do not intend to use E-learning in the future [17], [5], [1], [7]. A different study claims that "e-learning crack-up" perception has a significant impact on student's psychological distress [8]. One of the elements that may have contributed to students' discouragement in e-learning was most likely because of the lack of facilities such as the internet signal strength and devices compatibilities. Furthermore, majority of students are classified as B40, which denotes a low-income household.

Table 3: Student's Perception toward E-learning: Satisfaction

\begin{tabular}{|c|c|c|c|c|c|c|}
\hline Item & $S D(\%)$ & $D(\%)$ & $N(\%)$ & $A(\%)$ & $S A(\%)$ & Mean \\
\hline $\begin{array}{l}\text { I am satisfied with } \\
\text { the E-learning } \\
\text { conducted during this } \\
\text { pandemic }\end{array}$ & 4.3 & 11.3 & 44.1 & 32.8 & 7.5 & 3.28 \\
\hline $\begin{array}{l}\text { I am satisfied with } \\
\text { the online } \\
\text { assessments such } \\
\text { assignment, quiz, } \\
\text { test, and exam }\end{array}$ & 3.2 & 7.5 & 31.7 & 45.2 & 12.4 & 3.56 \\
\hline $\begin{array}{l}\text { I am satisfied with } \\
\text { lecturer's teaching } \\
\text { delivery through } \\
\text { online platform }\end{array}$ & 2.7 & 6.5 & 34.9 & 42.5 & 13.4 & 3.58 \\
\hline $\begin{array}{l}\text { I am interested to } \\
\text { continue learning } \\
\text { through online } \\
\text { medium }\end{array}$ & 13.4 & 18.8 & 33.3 & 26.3 & 8.1 & 2.97 \\
\hline
\end{tabular}

\subsection{Student's Perception toward E-learning: Benefits}

Given the abrupt transition from on-campus to online learning, which may have caused students discomfort, students were asked rate the benefits of e-learning using 12 questions, as shown in Table 4. This was done to show them that this technique of learning has benefits as well. Generally, there were mixed results: Students' average feedback ranged from 2.99 to 3.91 based on the mean score. The highest one is the ability for the students to access learning material anywhere and anytime and able to re-watch video recording. Other than that, the students found that online learning allows them to improve their technical skill in using electronic gadgets. Since that the respondents are Information Technology students, most of the students can use the technology available for E-learning easily. This finding also agreed by that [3] student's computer knowledge has a beneficial impact on the utilization of new technologies in e-learning.

Apart from that, more students thought that e-learning allows them to learn independently, costs less than learning on campus and more convenient since they do not require them to travel to attend lectures. On the other hand, yielded the opposite result: a significantly higher percentage of respondents found communicating digitally with instructors and students unsettling. This observation is consistent with the finding from [15]. 


\subsection{Students' Perceptions toward E-Learning: Challenges}

The descriptive statistics for students' reactions to the problems or challenges they faced when learning remotely during the COVID-19 epidemic are summarized in Table 5; this part has six items. More than half of the students said it was difficult to adjust their learning styles and maintain focus while learning online. This result contributed the result of the fourth and fifth items whereas most of the students have less motivation when learning online compared to face-to-face learning. Therefore, lecturers should create more engaging learning activities and come up with techniques to keep students' attention throughout sessions.

On the other hand, the result obtain for the first item are contradicted the demographic section regarding the internet signal strength, more than $90 \%$ of the students claim that they have a fair and good internet signal strength. However, the result shows that almost half of the students have poor, limited and unstable internet connection, which affect their online learning. The first item has the lowest mean score 2.98. Most of the students does not have poor learning condition at home, which affects my online learning. Students able to adapt with the learning styles and having a good self-discipline toward e-learning.

Table 4: Student's Perception toward E-learning: Benefits

\begin{tabular}{l|c|c|c|c|c|c}
\hline Item & $S D(\%)$ & $\boldsymbol{D}(\%)$ & $\boldsymbol{N}(\%)$ & $\boldsymbol{A}(\%)$ & $\boldsymbol{S A}(\%)$ & Mean \\
\hline $\begin{array}{l}\text { I do not need to travel } \\
\text { to campus to attend } \\
\text { online class }\end{array}$ & 13.4 & 13.4 & 19.9 & 24.2 & 29.0 & 3.42 \\
\hline $\begin{array}{l}\text { The expenses of } \\
\text { online learning are } \\
\text { less than those of } \\
\text { learning on campus }\end{array}$ & 5.9 & 10.2 & 28.5 & 31.2 & 24.2 & 3.58 \\
\hline $\begin{array}{l}\text { Online classes are } \\
\text { flexible }\end{array}$ & 1.6 & 4.3 & 27.4 & 34.9 & 31.7 & 3.27 \\
\hline $\begin{array}{l}\text { I can re-watch video } \\
\text { recording }\end{array}$ & 1.6 & 6.5 & 29.6 & 32.3 & 30.1 & 3.83 \\
\hline $\begin{array}{l}\text { I can access learning } \\
\text { materials anywhere } \\
\text { and anytime }\end{array}$ & 1.6 & 4.3 & 27.4 & 34.9 & 31.7 & 3.91 \\
\hline $\begin{array}{l}\text { It is comfortable to } \\
\text { attend online lectures } \\
\text { and learn online }\end{array}$ & 7.5 & 10.8 & 34.4 & 33.3 & 14.0 & 3.35 \\
\hline $\begin{array}{l}\text { It is comfortable to } \\
\text { interact with lecturers } \\
\text { through online } \\
\text { medium }\end{array}$ & 7.5 & 14.0 & 41.4 & 29.0 & 8.1 & 3.16 \\
\hline $\begin{array}{l}\text { It is comfortable to } \\
\text { interact with } \\
\text { classmates through } \\
\text { online medium }\end{array}$ & 10.8 & 21.0 & 34.9 & 24.7 & 8.6 & 2.99 \\
\hline $\begin{array}{l}\text { Online learning } \\
\text { allows me to learn to } \\
\text { be independent }\end{array}$ & 4.3 & 7.5 & 34.4 & 33.3 & 20.4 & 3.58 \\
\hline $\begin{array}{l}\text { Online learning } \\
\text { allows me to improve } \\
\text { my technical skill in } \\
\text { using electronic } \\
\text { gadgets }\end{array}$ & 2.7 & 4.3 & 28.5 & 37.1 & 27.4 & 3.82 \\
\hline $\begin{array}{l}\text { I can ask lecturers } \\
\text { questions and receive } \\
\text { a quick response } \\
\text { through online } \\
\text { medium }\end{array}$ & 3.8 & 13.4 & 36.6 & 35.5 & 10.8 & 3.36 \\
\hline $\begin{array}{l}\text { I can use the } \\
\text { technology available } \\
\text { for e-learning easily }\end{array}$ & & 5.4 & 33.9 & 38.2 & 19.4 & 3.65 \\
\hline
\end{tabular}

Table 5: Student's Perception toward E-learning: Challenges

\begin{tabular}{|c|c|c|c|c|c|c|}
\hline Item & $S D(\%)$ & $D(\%)$ & $N(\%)$ & $A(\%)$ & $S A(\%)$ & Mean \\
\hline $\begin{array}{l}\text { I have poor, limited } \\
\text { and unstable internet } \\
\text { connection, which } \\
\text { affects my online } \\
\text { learning }\end{array}$ & 11.3 & 19.4 & 35.5 & 21.5 & 12.4 & 3.04 \\
\hline $\begin{array}{l}\text { I have poor learning } \\
\text { conditions at home, } \\
\text { which affects my } \\
\text { online learning }\end{array}$ & 11.8 & 18.8 & 38.2 & 21.5 & 9.7 & 2.98 \\
\hline $\begin{array}{l}\text { I have lack of self- } \\
\text { discipline, which } \\
\text { affects my online } \\
\text { learning }\end{array}$ & 17.2 & 17.2 & 37.6 & 19.9 & 8.1 & 3.22 \\
\hline $\begin{array}{l}\text { It is difficult to adjust } \\
\text { my learning style }\end{array}$ & 7.0 & 12.9 & 41.9 & 27.4 & 10.8 & 3.58 \\
\hline $\begin{array}{l}\text { It is difficult for me } \\
\text { to stay focused } \\
\text { during online } \\
\text { learning }\end{array}$ & 6.5 & 9.1 & 30.6 & 28.0 & 25.8 & 3.58 \\
\hline $\begin{array}{l}\text { I have less motivation } \\
\text { when learning online } \\
\text { compared to face to- } \\
\text { face learning }\end{array}$ & 7.0 & 8.1 & 30.6 & 27.4 & 26.9 & 3.59 \\
\hline
\end{tabular}

\subsection{Differences in Students' Perceptions: Satisfaction based on Gender, Household Income and Area of Residence}

According to gender differences, there are slightly difference in the mean score for satisfaction of e-Learning: Benefits $($ Female $=3.35$, Male $=3.34)$. Household incomes are classified into three categories: B40 (less than RM 4,849), M40 (RM 4,850 to RM 10,959), and T40 (greater than RM 4,849). (RM 10,960 or more). Because most students are in the B40 group, it is expected that the mean satisfaction score for B40 will be the lowest. However, the T40 category has the lowest mean score for perception of e-Learning experience satisfaction $(\mathrm{B} 40$ and $\mathrm{M} 40=3.37 ; \mathrm{T} 20=2.25)$. More than half of the students' lives in urban area (61\%) therefore overall, the students that live in the urban area score higher mean of the perception toward e-Learning satisfaction (Urban $=3.41$; Rural = 3.34). This results, support that most of the students are having fair and good internet signal at their home. For daily spent time for e-Learning variable, surprisingly, the lowest time spent (less than 5 hours) for e-Learning score the highest mean (3.44).

\subsection{Differences Students' Perceptions: Benefits based on Gender, Household Income and Area of Residence}

For students' perception: benefits based on gender, the results are relatively equivalent in terms of gender score means $($ Female $=3.35$; Male $=3.49)$. This result is also similar for the result of differences in students' score mean of satisfaction and benefits towards e-Learning. Mean score for benefit for household income are 3.09. T20 score the lowest mean score 2.23. The mean score for second item "the expenses of online learning are less than those of learning on campus" most of them disagree with this notion since they believe they do not have any financial concerns. Furthermore, the areas of 
residence for urban and rural areas appear to be similar. The mean of both scores yields the same result (3.49).

4.6 Differences of Students' Perceptions: Challenges based on Gender, Household Income and Area of Residence

Based on gender differences female students have a higher score men rather than male students in term of challenges criteria. Both female and male students score the lowest mean is regarding that they have poor learning conditions at home, which affects their online learning $($ Female $=2.88$; Male $=$ 2.79). This element can be influenced by all the interruptions that may occur at home, such as an inconsistent internet connection and an unsupportive home atmosphere. In terms of student's perceptions of challenges based on household income, the results are as expected, ranging from the lowest to the greatest household income. $(\mathrm{T} 20=3.00 ; \mathrm{M} 40=3.19 ; \mathrm{B} 40$ $=3.23$ ). Therefore, a larger household income can provide students to have a better online learning environment. Whereas, when it comes to students' perception of the challenges in their area of residence, both areas share the same mean score $(M=3.21)$. In terms of residence area, the average score is nearly identical in both locations. Most students believe they have poor learning conditions at home, which has an impact on their online learning.

\subsection{Students Suggestion to Improve of E-Learning}

Respondents were also asked to make suggestions on how to improve future e-Learning experiences for students. According to Figure 1, most students recommended a workload reduction of $35.8 \%$. Then there's providing lengthier assessment time $28.9 \%$, improving teaching style and learning activities $19.8 \%$, reducing live session duration $8.6 \%$, and improving learning materials or content $7 \%$. Consequently, lecturers are advised to consider this suggestion in creating a better e-learning environment to the students.

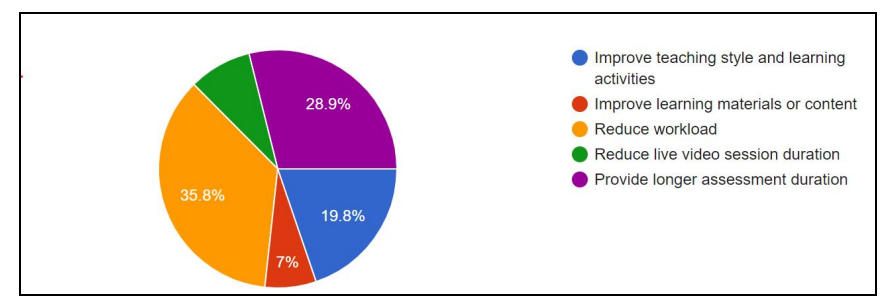

Figure 1: Students Suggestion to Improve E-Learning

\section{CONCLUSION}

The results of this study revealed that respondents' satisfaction was mainly neutral to favorable. The highest item for. student's satisfaction is the lecturer's teaching delivery through online platform Unfortunately, most of the students are not interested to continue learning through online leaning in the future. Among the benefits of e-learning, majority think that it is easy to access learning material anywhere and anytime. Since the teaching materials are available online students feel that it is easier and more flexible. In addition, most of the students also consider that e-learning help them in improving the technical skill of in the usage of electronic gadgets such as microphone, camera, and tablets. These skills are essential for them to help them communicate and joining the class meeting. Unfortunately, most students are uncomfortable communicating with their classmates and lecturers. Of course, these results have a negative impact to the quality of the student learning experience. The challenges of e-learning,

\section{REFERENCES}

1. Abbasi, Sahar, et al. Perceptions of Students Regarding E-Learning during Covid-19 at a Private Medical College. Pakistan Journal of Medical Sciences, vol. 36, no. COVID19-S4, 2020.

2. Adedoyin, Olasile Babatunde, and Emrah Soykan. Covid-19 Pandemic and Online Learning: The Challenges and Opportunities. Interactive Learning Environments, 2020, pp. 1-13.

3. Alameri, Jehad, et al. Students' Perceptions of E-Learning Platforms (Moodle, Microsoft Teams and Zoom Platforms) in The University of Jordan Education and Its Relation to Self-Study and Academic Achievement During COVID-19 Pandemic. Advanced Research \& Studies Journal, vol. 11, no. 5, 2020, pp. 21-23,

4. Alkhalaf, Salem, et al. Assessing the Impact of E-Learning Systems on Learners: A Survey Study in the KSA. Procedia - Social and Behavioral Sciences, vol. 47, 2012, pp. 98-104.

5. Alqudah, Noor M., et al. Perception and Experience of Academic Jordanian Ophthalmologists with E-Learning for Undergraduate Course during the COVID-19 Pandemic. Annals of Medicine and Surgery, vol. 59, 2020, pp. 44-47.

6. Baber, Hasnan. Modelling the Acceptance of E-Learning during the Pandemic of COVID-19-A Study of South Korea. The International Journal of Management Education, vol. 19, no. 2, 2021, p. 100503.

7. Dwidienawati, Diena. Forced Shifting to E-Learning during the COVID-19 Outbreak: Information Quality, System Quality. International Journal of Advanced Trends in Computer Science and Engineering, vol. 9, no. 2, 2020, pp. 1518-25.

8. Hasan, Najmul, and Yukun Bao. Impact of 'e-Learning Crack-up' Perception on Psychological Distress among College Students during COVID-19 Pandemic: A Mediating Role of 'Fear of Academic Year Loss. Children and Youth Services Review, vol. 118, 2020, p. 105355.

9. Jin, Yuan Qing, et al. A Study on Traditional Teaching Method Transferring to E-Learning Under the Covid-19 Pandemic: From Chinese Students' Perspectives. Frontiers in Psychology, vol. 12, 2021. 
10. Karim, M. W., Haque, A., Ulfy, M. A., \& Hossin, M. S. (2021). Factors Influencing Student Satisfaction towards Distance Learning Apps During the Coronavirus (Covid-19) Pandemic in Malaysia. International Journal of Academic Research in Progressive Education and Development, vol. 10(2), 245-260

11. Khan, Mohammed Arshad, et al. Students' Perception towards E-Learning during COVID-19 Pandemic in India: An Empirical Study. Sustainability, vol. 13, no. 1, 2020 , p. 57.

12. Kulal, Abhinandan, and Anupama Nayak. "qA Study on Perception of Teachers and Students Toward Online Classes in Dakshina Kannada and Udupi District. Asian Association of Open Universities Journal, vol. 15, no. 3, 2020, pp. 285-96.

13. Nikou, Shahrokh, and Ilia Maslov. An Analysis of Students' Perspectives on e-Learning Participation the Case of COVID-19 Pandemic. The International Journal of Information and Learning Technology, vol. 38, no. 3, 2021, pp. 299-315.

14. Maatuk, Abdelsalam M., et al. The COVID-19 Pandemic and E-Learning: Challenges and Opportunities from the Perspective of Students and Instructors. Journal of Computing in Higher Education, 2021.

15. Mahyoob, M. (2020b). Challenges of e-Learning during the COVID-19 Pandemic Experienced by EFL Learners. Arab World English Journal, 11(4), 351-362.

16. Osman Abdelmola, Amani, et al. E- Learning during COVID-19 Pandemic, Faculty Perceptions, Challenges, and Recommendations. MedEdPublish, vol. 10, no. 1, 2021.

17. R.Radha, et al. E-Learning during Lockdown of Covid-19 Pandemic: A Global Perspective. International Journal of Control and Automation, vol. 13, no. 4, 2020, pp. 1088-99,

18. Razami, Husna Hafiza, and Roslina Ibrahim. Distance Education during COVID-19 Pandemic: The Perceptions and Preference of University Students in Malaysia Towards Online Learning. International Journal of Advanced Computer Science and Applications, vol. 12, no. 4, 2021.

19. Shahzad, Arfan, et al. Effects of COVID-19 in E-Learning on Higher Education Institution Students: The Group Comparison between Male and Female. Quality \& Quantity, vol. 55, no. 3, 2020, pp. 805-26.

20. Sharin, Ana Nurdini. E-Learning During Covid-19: A Review of Literature. Malaysian Journal of Media Studies, vol. 23, no. 1, 2021, pp. 15-28,

21. Taber, Keith S. The Use of Cronbach's Alpha When Developing and Reporting Research Instruments in Science Education. Research in Science Education, vol. 48, no. 6, 2017, pp. 1273-96.

22. Toti, Giulia, and Mohammad Amin Alipour. Computer Science Students' Perceptions of Emergency Remote
Teaching: An Experience Report. SN Computer Science, vol. 2, no. 5, 2021.

23. Vadakalu Elumalai, Kesavan, et al. Factors Affecting the Quality of E-Learning During the COVID-19 Pandemic from the Perspective of Higher Education Students. Journal of Information Technology Education: Research, vol. 19, 2020, pp. 731-53.

24. Yeo, Sing Chen, et al. A Targeted E-Learning Approach for Keeping Universities Open during the COVID-19 Pandemic While Reducing Student Physical Interactions. PLOS ONE, edited by Jim P. Stimpson, vol. 16, no. 4, 2021, p. e0249839.

25. Zalat, Marwa Mohamed, et al. The Experiences, Challenges, and Acceptance of e-Learning as a Tool for Teaching during the COVID-19 Pandemic among University Medical Staff. PLOS ONE, edited by Gwo-Jen Hwang, vol. 16, no. 3, 2021, p. e0248758. 